microangioscope embedded in a $0.0165^{\prime}$ microcatheter. In human cadaveric experiments, that the microangioscope is compatible with the human intracranial vasculature beyond the Circle of Willis (eg. navigation into and visualization of the M2 origin). In in vivo swine model experiments, the microangioscope has adequate resolution and illumination to identify and differentiate between various intravascular pathologies (eg. red thrombus versus white thrombus). With flow arrest and irrigation, mechanical thrombectomy (both with stent retriever and direct aspiration), coil embolization, stent deployment, and balloon angioplasty were precisely performed under direct visualization with the microangioscope. After deployment, the microangioscope enables direct inspection of devices, providing complementary information to standard angiography. Imaging quality, illumination, and flexibility of the microangioscope progressively improved through modifications to the image bundle. Based on these results, the microangioscope is compatible with the human distal cerebrovasculature; it also provides adequate direct visualization for neurointerventions.

Disclosures V. Srinivasan: None. T. Lazaro: None. P. Cooper: 5; C; Vena Medical, Inc. M. Phillips: 5; C; Vena Medical, Inc. R. Garcia: None. S. Chen: None. J. Johnson: None. J. Burkhardt: None. D. Collins: None. P. Kan: 2; C; Medtronic, Cerenovus.

\section{P-015 LONG-TERM ECONOMIC IMPACT OF THE FIRST PASS EFFECT (FPE) IN THE TREATMENT OF STROKE WITH THE EMBOTRAP II DEVICE (IN ARISE-II)}

${ }^{1} \mathrm{O}$ Zaidat ${ }^{*},{ }^{2} \mathrm{~J}$ Saver, ${ }^{3} \mathrm{H}$ Mattle, ${ }^{4} \mathrm{M}$ Ribo, ${ }^{5} \mathrm{~A}$ Narata, ${ }^{6} \mathrm{~A}$ Yoo, ${ }^{7} \mathrm{H}$ Bozorgchami, ${ }^{8} \mathrm{C}$ Crivera, ${ }^{9} \mathrm{H}$ Cameron, ${ }^{10} \mathrm{~T}$ Andersson. ${ }^{1}$ St. Vincent Mercy Medical Center, Toledo, $\mathrm{OH}_{;}{ }^{2}$ Department of Neurology, University of California, Los Angeles, Los Angeles, CA; ${ }^{3}$ Department of Neurology, University Hospital Bern, Bern, Switzerland; ${ }^{4}$ Department of Neurology, Hospital Vall d'Hebron, Barcelona, Spain; ${ }^{5}$ Service of Radiology and Neuroradiology, University Hospital Tours, Tours, France; ${ }^{6}$ Interventional Neuroradiology/Neuroendovascular Surgery, Texas Stroke Institute, Plano, TX; ${ }^{7}$ Oregon Health and Science University, Portland, OR; ${ }^{8}$ Cerenovus, Johnson and Johnson, IIvine, CA; ${ }^{9}$ Cornerstone Research Group, Burlington, ON, Canada; ${ }^{10}$ Departments of Neuroradiology and Clinical Neuroscience, Karolinska University Hospital and Karolinska Institutet, Stockholm, Sweden

\subsection{6/neurintsurg-2019-SNIS.51}

Introduction The first pass effect (FPE) is the ability to restore near or complete revascularization (modified Thrombolysis in Cerebral Ischemia $[\mathrm{mTICI}] \geq 2 \mathrm{c}$ ) of acutely blocked cerebral arteries in a single thrombectomy device pass. FPE has been shown to be an independent predictor of good functional outcomes (modified Rankin Scale [mRS] $\leq 2$ ), a goal of stroke therapy that impacts healthcare costs, and is associated with reduced 90-day mortality and fewer adverse events. A separate analysis of ARISE-II data showed that the FPE was associated with reduced procedural and in-patient healthcare resource use (length of stay, days in the intensive care unit, standard bed days, and devices used) and accompanying short-term costs; however, the long-term economic impact of achieving the FPE has not been assessed.

Methodology Data were obtained from a single-arm, prospective, multicenter study assessing the EMBOTRAP II device, ARISE-II $(n=227)$. Patients who did not achieve complete revascularization were excluded. Among those who achieved complete revascularization $(\mathrm{mTICI} \geq 2 \mathrm{c})$, the proportion of patients achieving each mRS score was assessed, stratified by the FPE status. Long-term costs per mRS score, obtained from a 2015 U.S. cost-effectiveness analysis that projected annual post-hospitalization inpatient/outpatient and nursing home costs using data from the National Death Index and Centers for Medicare and Medicaid Services (CMS), were applied to all patients. Post-hospitalization costs, in 2018 USD, were then compared between patients that did or did not achieve the FPE and incremental differences were calculated for a 1-year time horizon.

Results In ARISE-II, 76\% of patients $(n=172)$ achieved complete revascularization; among these patients, 53\% achieved the FPE. A significantly higher percentage of patients that achieved the FPE had good functional outcomes vs. those that did not achieve the FPE $(80.5 \%$ vs. $61.0 \%, \mathrm{p}=0.006)$. Estimated annual post-hospitalization costs were lower among patients that achieved FPE vs. those that did not achieve FPE, leading to estimated per-patient cost-savings of $\$ 3,876$ (table 1 ). In the absence of cost data reported in ARISE-II, costs for healthcare resource use were obtained from the literature, which may not be generalizable across settings and is a limitation of this analysis. Additionally, the cost-effectiveness analysis used to inform the long-term costs per mRS score did not report costs for death (i.e., mRS 6), which had a lower incidence among patients who achieved the FPE vs. those who did not achieve the FPE $(5.75 \%$ vs. $14.29 \%)$.

Abstract P-015 Table 1 Per-patient costs for the first year after stroke based on functional outcomes

\begin{tabular}{|c|c|c|c|c|c|c|}
\hline $\mathrm{mRS}$ & $\begin{array}{l}\% \text { Achie } \\
\text { Level }\end{array}$ & ing mRS & $\begin{array}{l}\text { Cost } / \mathrm{mRS} \\
\text { Level }\end{array}$ & Cost/Patient & & \\
\hline & $\begin{array}{l}\text { FPE } \\
(n=91)\end{array}$ & $\begin{array}{l}\text { Not Achieving } \\
\text { FPE }(n=81)\end{array}$ & & FPE & $\begin{array}{l}\text { Not Achieving } \\
\text { FPE }\end{array}$ & Difference \\
\hline 0 & $41.38 \%$ & $19.48 \%$ & $\$ 11,466.92$ & $\$ 14,531.19$ & $\$ 18,407.35$ & $-\$ 3,876.16$ \\
\hline 1 & $21.84 \%$ & $27.27 \%$ & $\$ 11,807.59$ & & & \\
\hline 2 & $17.24 \%$ & $14.29 \%$ & $\$ 13,659.62$ & & & \\
\hline 3 & $9.20 \%$ & $7.79 \%$ & $\$ 23,454.61$ & & & \\
\hline 4 & $2.30 \%$ & $11.69 \%$ & $\$ 47,472.32$ & & & \\
\hline 5 & $2.30 \%$ & $5.19 \%$ & $\$ 69,792.07$ & & & \\
\hline 6 & $5.75 \%$ & $14.29 \%$ & - & & & \\
\hline
\end{tabular}

Conclusion Among patients with final complete reperfusion (mTICI $\geq 2 \mathrm{c})$, achieving FPE may lead to long-term per-patient cost-savings of $\$ 3,876$ in the first year due to improved functional outcomes.

Disclosures O. Zaidat: 1; C; Cerenovus, Stryker, Medtronic, Penumbra, Genentech, Tesla Clinical Trial. 2; C; Cerenovus, Stryker, Medtronic, Penumbra. J. Saver: 2; C; Cerenovus, Stryker, Medtronic, Rapid Medical. H. Mattle: 1; C; Neuravi/Cerenovus. 2; C; Neuravi/Cerenovus. 3; C; Neuravi/Cerenovus. M. Ribo: 1; C; Stryker, Medtronic. 2; C; Cerenovus, Stryker, Medtronic, Anaconda Biomed. 4; C; Anaconda Biomed. A. Narata: None. A. Yoo: 1; C; Cerenovus, Stryker, Medtronic, Penumbra, Genentech. 2; C; Cerenovus, Genentech, Zoll Circulation. 4; C; Insera Therapeutics. H. Bozorgchami: 2; C; Cerenovus, Stryker, Coherex. C. Crivera: 4; C; Johnson \& Johnson. 5; C; Johnson \& Johnson. H. Cameron: 2; C; Employee of Cornerstone Research Group, contracted by Cerenovus. T. Andersson: 2; C; Cerenovus, Anaconda, Medtronic, Ablynx, Amnis Therapeutics, Rapid Medical. 